cell biology and the editor should have every encourage. ment to continue them.

J. M. Mitchison

\section{ENERGY FOR LIVING}

\section{Current Topics in Bioenergetics}

Vol. 1 Edited by D. R. Sanadi. Pp. xi+292. (New York: Academic Press, Inc.; London: Academic Press, Inc. (London), Ltd., 1966.) $92 s$.

This is the first volume of a new series which is intended "to bring together authoritative and timely reviews on the closely rolated multidisciplinary research in such fields as photosynthesis, bioluminescence, nerve conduction, oxidative phosphorylation, muscle contraction, stretch reception, phototaxis and protoplasmic streaming". The aim is to emphasize the molecular basis of these energy transduction systems, but where appropriate higher organizational levols will also be discussed.

It is difficult to predict from the contents of the first volume how successful the series will be, but it is probably fair to say that many workers will welcome this attompt to provide a forum for the discussion of the various topics in bioenergetics. Its success will, of course, depend to a large extent on the originality and scope of the articles and topics selected. The first volume, however, sets a fairly good standard in this respect.

The first three articles are concernod with photosynthosis. The first of these, by B. Kok and G. M. Cheniae, is a timely review of the oxygen evolution step in photosynthosis. The second is an excellent discussion of fluorescence yield in photosynthetic systems and its relation to electron transport by W. L. Butler, while the third is a stimulating account of uncoupling and energy transfor inhibition in photophosphorylation by N. Good, S. Izawa and G. Hind. There follows a comprehensive article on bioluminescence by $J$. W. Hastings and two intoresting onos on muscle; structure and function of myosin is discussed by $\mathbf{A}$. Stracher and P. Dreizen, and energized calcium transport and relaxing factors by $A$. Weber. The book ends with a short roviow of ion transport in mitochondria by E. J. Harris, J. D. Judah and K. Ahmed.

Chemists, biochemists and biologists working in this active and often controversial field of research will find much to interest them in this volume and the rest of the series, which should also provide an oxcellent source of references to the current literature. E. R. REDFEARN

\section{MICROBES IN THE LABORATORY}

\section{Laboratory Methods in Microbiology}

By W. F. Harrigan and Margaret E. McCance. Pp. xi+ 362. (London: Academic Press, Inc. (London), Ltd.; New York: Academic Pross, Inc., 1966.) 79s.; $\$ 13.50$. Tue authors state that their "primary object... is to provide a laboratory handbook for use by students of food science, dairying, agriculture and allied courses, in addition to being of value to students reading microbiology or bactoriology". The title of this book is somewhat misleading and the reader anticipating a broad coverage of microbiological methods may be disappointed. Predominantly this is a manual of practical bacteriology - the fungi rocoive rather scant attention while the other protists are mentioned hardly at all-and is strongly orientated towards food and public health requirements. Part I of the book deals with basic mothods and includes details of microbial culture and culture media, simple staining procedures, onumeration, biochemical tests for bactoria and some introductory sorology. Also in this section are useful directions on the cleaning of glassware and equipment, and sterilization. Finally, moulds, yeasts and coliphage are considered. This latter material is treated all too briefly and deserves a more thorough representation in a book of such comprehensive title.

The second third of the book describes the techniques peculiar to applied microbiology, but, with the exception of sections on the examination of water, soil and silage, the accent is on the bacteriological examixiation of foodstuffs and equipment. angin certain items appear to me to have been undor-troated, for example, the delibera. tions on soil microbiology are too selective and consequently unbalanced. Generally the descriptions of the microbiological analyses of foods are comprehensive, carefully organized and constitute one of the principal attractions of the volume. The authors conclude their book with two major appendixes. The first comprises schemes for the identification of micro-organisms, and is in the form of simplified tables and keys, followed up by concise group and genus descriptions. The second appendix contains the recipes and details for preparing a wide range of microbiological reagents and growth media. Pleasing features throughout are the most useful indications of relovant laboratory suppliers and the well arranged lay-out indispensable to any laboratory manual. On the other hand, much of the information contained in this volume is to be found in other practical handbooks which have the additional virtues of greater breadth of subject and lower price.

ALAN T. BULI.

\section{DRUGS AND THE MAN}

International Encyclopedia of Pharmacology and Therapeutics

Executive Editor: C. Radouco-Thomas. Section 6: Clinical Pharmacology. Editor: L. Lasagna. Vol. 1: Pp. xiii+1-374. 80s. Vol. 2: Pp. $\mathrm{xxx}+375-667$. 63s. (Oxford, London and New York: Pergamon Press. Ltd., 1966.)

Most books on clinical pharmacology describe the actions of drugs in man, summarizing the results of research in clinical pharmacology and relating them to therapeutics. Such books are essential for medical students and their teachers, but until now there have been very few books about the methods used in human pharmacology and the special problems of assessing drug effects in different clinical situations. These volumes provide hard-headed advice on the investigation of drugs in man, and on the interpretation of the findings.

Clinical pharmacology exists because many critical questions about the use of drugs can only be answered by experiments in man. This is really the theme of the book, and every chapter illustrates it in detail. The contributors are all experienced in their fields and write with refreshing directness. They discuss the study of drugs not only in patients, but also in healthy volunteers and, where relevant, in the laboratory. Every chapter is clear and interesting to read--a remarkable editorial achieve. ment.

The thirty-three chapters by forty-four authors are arranged by organ systems. Lasagna's excellent intro. duction on the many faces of clinical pharmacology begins each volume. Volume 1 deals with the central nervous system (sixteen chapters) and the endocrines; Volume 2 deals with cardiovascular and renal pharma. cology (six chapters), anticoagulants, drugs used in arthritis, bacterial infections, malignant diseases and respiratory allergies, and with adverse reactions to drugs. Multiclinic trials and the use of computers are two recent developments that are becoming important and are well discussed in several chapters. The author and subject indexes are not comprehensive enough; by an oversight they appear only in Volume 2.

Subjects that have been omitted are of two kinds: those for which suitable authors were not found though they 